\title{
DISTAL TRANS-RADIAL APPROACH FOR CORONARY ANGIOGRAPHY AND PERCUTANEOUS CORONARY INTERVENTIONS - SINGLE-CENTRE EXPERIENCE
}

\author{
MAGED MOKBEL ${ }^{1}$, NICOLAE FLORESCU ${ }^{2}$, CRINA JULIETA SINESCU ${ }^{3}$ \\ 1,3 “Carol Davila” University of Medicine and Pharmacy Bucharest, ${ }^{1}$ "Sfântul Ioan” Clinical Emergency Hospital, București, ${ }^{2}$ Polisano Clinic, Sibiu, \\ 3 "Bagdasar Arseni” Clinical Emergency Hospital, București
}

\begin{abstract}
Keywords: $\quad$ snuff-box, Abstract: Right distal transracial approach in the anatomical snuff box could reduce the probability transradial, of radial artery occlusion. Also, that approach allows a more comfortable hand position, especially in coronarography obese patients. We prospectively evaluated right distal transracial approach (DTRA) in patients treated trans-radially. Materials and methods: Prospective, observational, single centre study. Various relevant objectives were assessed, for example radial artery occlusion in the evaluated patients at discharge by ultrasonography, procedural success, time of scopy and time required for haemostasis. 57 eligible patients were included in the study. The mean age was 63 years, $63 \%$ men, and PCI was performed in $37 \%$ of patients. In all patients we used 6Fr radial sheaths, standard catheters and TR-band with verification after one hour, then within 30-minute intervals. Results: Procedural success was $89.5 \%$, no patients had radial artery occlusion, two patients had a local hematoma remitted later, the medium time required for hemostasis was 83.5 minutes, no patients suffered ischaemia or any effect in right hand's functions. Conclusion: Distal radial puncture seems feasible, safe and can be considered routinely.
\end{abstract}

\section{INTRODUCTION}

Atherosclerotic coronary heart disease is the most common cause of death in adults. Coronary atherosclerosis causes stenosis or coronary occlusion, leading to myocardial ischemia or necrosis. Coronary angiography and percutaneous coronary intervention (PCI) are important tools for the diagnosis and treatment of ischaemic heart disease. The pathways for coronary angiography and PCI include the femoral artery, radial artery, brachial artery, and ulnar artery.

With the improvement of technology and equipment, transradial coronary intervention has become the preferred approach for interventional cardiology procedures in the world.(1)

The anatomical snuff-box is an empty space located on the back of the hand and can be clearly seen after the thumb is fully extended. The ulnar margin of anatomical snuff-box is formed by the tendon of the extensor pollicis longus. The radial boundary includes the tendons of the abductor pollicis longus and extensor pollicis brevis. The basis is the scaphoid and trapezius bones. The distal part of the radial artery passes through the anatomical snuff-box.(2) In 2017, Kiemeneij reported the trans-radial arterial approach in the anatomical snuff box of his left arm and the result suggested that the procedure was safe and feasible.(3) This new approach may overcome some disadvantages of the conventional trans-radial approach in several respects.

\section{AIM}

The purpose of this study is to evaluate the safety and feasibility of trans-radial access in the anatomical snout of the right forearm.

\section{MATERIALS AND METHODS}

This is a prospective, single-centre observational study. Ethical approval was obtained from the hospital committee. Patients were selected from those scheduled for coronary angiography or PCI at the Polisano Clinic in Sibiu, Romania, between January and February 2018. Informed consent was obtained both verbal and written for each patient

Patient's selection

Our study included 57 patients. The most important inclusion criterion was the presence of a pulse in the anatomical snuff-box. All patients underwent Barbeau's test before the procedure to assess the permeability of the distal vascular bed.

\section{Exclusion criteria}

1. Absence of pulse.

2. Known malformation of forearm's arteries.

3. Severe hepatic / renal impairment or known coagulopathy

4. Cardiogenic shock.

5. History of coronary bypass with a radial arterial graft.

Technique (figure no. 1)

1. The patient is placed in supine position on the angiography table.

2. The right arm is comfortably positioned next to a side extension.

3. The operator who had extensive experience (over 100 radial procedures performed) stands on the patient's right side and reconfirms the puncture site.

4. After the subcutaneous injection of $1 \mathrm{ml}$ lidocaine through a $5 \mathrm{ml}$ needle, the Seldinger's technique was performed in the anatomical snuff-box.

5. $21 \mathrm{G}$ needle, a metallic guide-wire and $6 \mathrm{Fr}$ radial sheath were used in all patients.

${ }^{3}$ Corresponding author: Sinescu Crina Julieta, Şos. Berceni, Nr. 12, București, România, E-mail: crinasinescu@ gmail.com, Phone: +40722 300301 Article received on 20.01.2021 and accepted for publication on 02.03.2021 
6. Unfractioned heparin is administered intra-arterially after sheath insertion, dose of $50 \mathrm{u} . \mathrm{i} / \mathrm{kg}$, subsequently increased to $80-100 \mathrm{u} . \mathrm{i} / \mathrm{kg}$ in case of PCI.

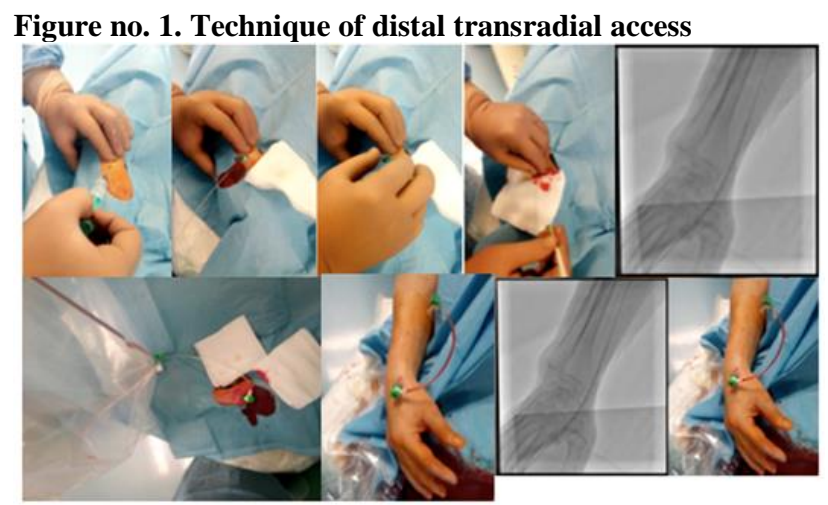

Haemostasis

Gradual deflation technique was used as follows (figure no. 2):

- TR-Band inflation with $20 \mathrm{ml}$ of air at a time, then remove the sheath

- Slow deflation till the slightest sign of bleeding at the site of access.

- $\quad 2 \mathrm{ml}$ of air are inflated and the total amount of air used is noted.

- The same technique of slow deflation is repeated after an hour, then at an interval of 30 minutes.

- TR-Band is removed as soon as there's no sign of local bleeding.

- Total haemostasis time is noted.

\section{Figure no. 2. Removing distal trans-radial sheath}

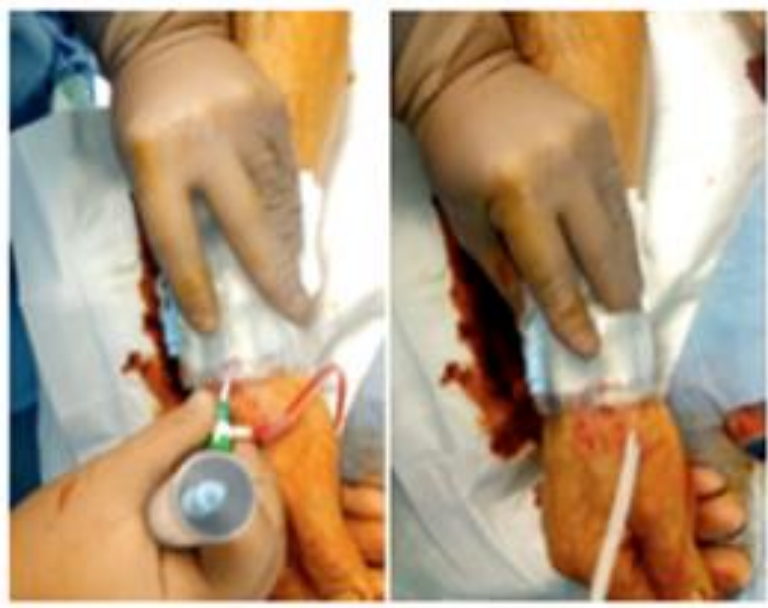

Data collection

1. Initial characteristics of patients (age, sex, coronary risk factors).

2. Number of trials.

3. Access time in seconds.

4. Total fluoroscopy time in seconds.

5. Haemostasis time in minutes.

6. Hospitalisation time in days.

7. Postoperative complications (major and minor bleeding, hematoma, vasospasm, arteriovenous fistula, radial artery occlusion (RAO), loss of arm functions).

\section{Statistical analysis}

Statistical analysis was performed using the statistical software PSPP 1.0.1 MacOS. The measurement data were all expressed as means \pm standard deviation.

\section{RESULTS}

From January to February 2018, a total of 57 patients were included in this study. The mean age of the patients was $62.93 \pm 9.71$ years, $63 \%$ were men (table no. 1 ).

Table no. 1. Mean age of patients

\begin{tabular}{|l|l|r|}
\hline Age & \multicolumn{2}{|c|}{} \\
\hline $\mathrm{N}$ & Valid & 57 \\
\cline { 2 - 3 } & Missing & 0 \\
\hline Mean & & 62.93 \\
\hline Std Dev & & 9.71 \\
\hline Minimum & & 45.00 \\
\hline Maximum & & 82.00 \\
\hline
\end{tabular}

Hypertension, dyslipidemia, diabetes and smoking were present in $68.4 \%, 56.1 \%, 35.1 \%$ and $29.8 \%$, respectively. A degree of renal impairment greater than or equal to 2 was present in $24.6 \%$ of patients (figure no. 3 ).

Figure no. 3. Patient's characteristics and relevant history

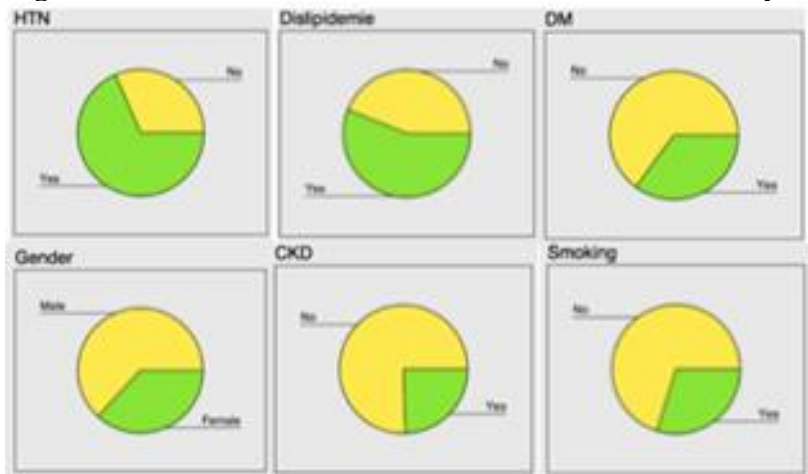

There were 6 failures, requiring the conventional approach of the right radial artery or right femoral artery. In 3 patients, the puncture failed due to severe distal vasospasm that did not allow the introduction of 0.02 " guide-wire even in the presence of a good arterial flow through the needle, while in the other 3 patients there were more than 3 attempts to cannulate the artery without any success. The total number of successful cases was 51 , with a success rate of $89.5 \%$, in all patients $6 \mathrm{Fr}$ catheters were used, both diagnostic and guiding. Of the successful cases, $37.2 \%$ had coronary angioplasty $(n=19)$, with an average of 1.52 stents / patient $(\mathrm{n}=29)$.

Figure no. 4. Post procedural local hematoma

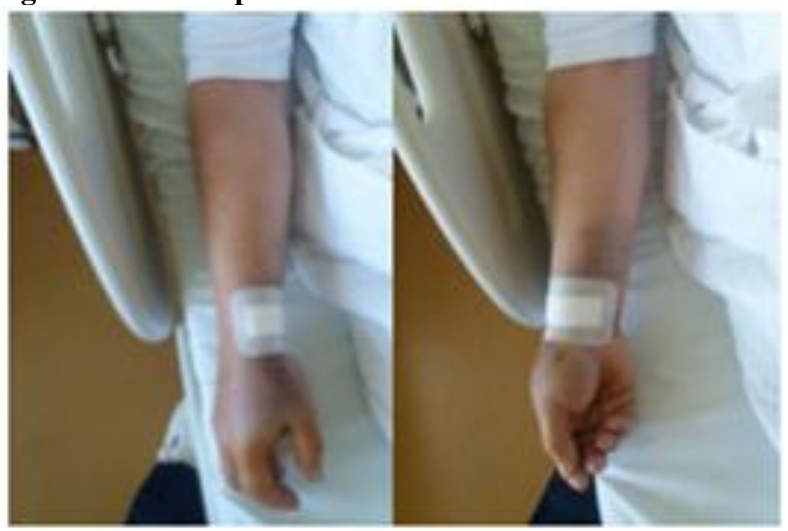

On average, the number of puncture attempts was 1.33 \pm 0.59 with a maximum number of 3 attempts used, otherwise it is considered a failed case. The mean overall artery access time (calculated after local anaesthesia) was $65.22 \pm 36.37$ seconds, ranging from 32 to 176 seconds.

The mean time of post-procedural haemostasis was $83.53 \pm 25.68$ minutes. The mean length of hospital stay was 


\section{CLINICAL ASPECTS}

$1.98 \pm 1.14$ days. The mean X-ray exposure time was $252.12 \pm$ 169.23 seconds. No patients complained of significant discomfort during the procedure.

Two patients $(3.9 \%)$ had local hematoma after the procedure, probably due to multiple punctures. After the dressing under pressure, the hematoma improved without ultrasonographic signs of radial artery occlusion and the activity of the hands was not affected (figure no. 4).

Three patients $(5.9 \%)$ had intra-procedural vasospasm, treated medically and with the help of more hydrophilic catheterisation materials. No major bleeding, arteriovenous fistulas, radial artery occlusion or other significant complications were observed. No patient complained of hand or arm dysfunction.

\section{DISCUSSIONS}

Radial artery and femoral artery are commonly used as arterial approaches for coronary angiography and PCI. In recent years, trans-radial access has become more rapidly widespread. A large number of studies have confirmed that trans-radial access can eliminate some of the shortcomings of femoral access. Patients with trans-radial access feel more comfortable, have less local pain and complications; radial access reduces mortality and major adverse cardiac events in patients with STEMI.(4) Anatomically, the radial artery is more superficial than the femoral artery and can be easily compressed. The end of the radial artery is anastomosed with the deep palmar branch of the ulnar artery to form deep palmar arch with an effective collateral circulation. The incidence of hand ischaemia, necrosis or dysfunction after trans-radial artery puncture is low.(5) However, the standard radial artery approach has its disadvantages. The most common complication is radial artery occlusion (RAO).(6)

After Kiemeneij (3) first reported left distal transradial access in the anatomical snuff-box for interventional therapy, several studies (7) found that interventional therapy through this approach is feasible.

The new access has become a new hot spot. Left distal radial artery access offers a new approach to coronary intervention, especially in patients with right RAO or if the right radial artery used for coronary bypass grafting. This new approach can improve both patient's and operator's comfort, allowing a more comfortable position during the procedure and apparently a shorter postoperative haemostasis time is required. In addition, there may be a reduced risk of RAO.

Our study found that coronary intervention through the distal right trans-radial approach seems safe and feasible, the haemostasis time is short, using minimal resources.

No major complications were reported, and patients tolerated it well. The main advantages of access to the distal radial artery appear to be:

1. Less haemostasis time.

2. More patient's comfort

3. More operator's comfort

4. For patients requiring coronary artery bypass grafting, distal access may reduce the likelihood of vascular injury, especially to the radial artery's trunk.

From an anatomical point of view, the radial artery in the anatomical snout is located at the distal end of the radial artery. Its diameter at the puncture site is obviously smaller, access is more difficult and the learning curve is longer. In this study, the success rate of distal radial artery access was up to $89 \%$, the number of punctures was 1-3 times, minimising the risk of peripheral nerve damage, arteriovenous fistula and thrombosis. With the continuous accumulation of the puncture experience, the number and timing of the punctures will be improved.
Whether the approach is left or right, placing the arm during the procedure is more comfortable than conventional access to the radial artery. For obese patients and patients with shoulder or elbow disorders, the placement requirements of the arms during the procedure can be better achieved and patient comfort can be improved. Although the sample size of this study was small, it was consistent with other studies on patient comfort.

The radial artery, the cephalic vein and the superficial branch of the radial nerve pass through the anatomical snuffbox.(8) Radial nerve injury is a common injury to the peripheral nerve that can cause abnormal sensations in the back of the hand. A close relationship was found between the radial nerve and the radial artery.(9) Although there were no neurological problems in this study, we still argue more studies to further clarify the relationship between radial artery and nerve distribution in anatomical snuff-box. In some previous studies, in more than $85 \%$ of patients, the diameter of the radial artery was larger than that of the $6 \mathrm{Fr}(2.52 \mathrm{~mm})$ sheath.(10) Currently, most cardiac centers choose $6 \mathrm{~F}$ sheaths for PCI through the radial artery, and most procedures can be performed with this sheath size. In this study, we used only $6 \mathrm{Fr}$ sheaths in all patients and managed to successfully complete all the procedures. Because the size of the distal radial artery is smaller (usually less than $2 \mathrm{~mm}$ ), femoral artery access and standard radial artery access are still recommended for interventions requiring $7 \mathrm{~F}$ sheath.

If patients need coronary artery bypass grafting $(\mathrm{CABG})$, the radial artery has a higher permeability rate than the great saphenous vein, when used in addition to the internal mammary artery graft. Studies have found that catheterised radial arteries have a modified morphology and function and it is not recommended anymore to be used for coronary artery bypass grafting, however, even then it remains an important option compared to venous grafts.

The distance between artery and puncture site can reduce the likelihood of injury to the radial artery trunk, which can bring some benefits, an assumption that requires further studies as to be confirmed.

\section{Limitations}

This observational study represents a single centre's experience, with a relatively small number of patients. Multiple multi-centre studies are needed to compare distal access with conventional one, in terms of procedural success, complications, postoperative haemostasis time, amount of contrast agent, time of X-ray exposure, etc.

\section{CONCLUSION}

Coronary angiography and percutaneous coronary interventions appear to be safe and feasible through the distal puncture of the right radial artery. In our experience, this approach can routinely be considered by interventional cardiologists.

Acknowledgement:

"I undersign, certificate that I don't have any financial or personal relationships that might bias the content of this work", Maged Mokbel

\section{REFERENCES}

1. Bertrand OF, Rao SV, Pancholy S, et al. Transradial approach for coronary angiography and interventions: results of the first international transradial practice survey. JACC Cardiovasc Interv. 2010;3:1022-31.

2. Cerda A, del Sol M. Anatomical snuffbox and it clinical significance. A Literature Review. Int J Morphol. 2015;33:1355-60.

3. Kiemeneij F. Left distal transradial access in the anatomical 


\section{CLINICAL ASPECTS}

snuffbox for coronary angiography (ldTRA) and interventions (ldTRI). Euro Intervention. 2017;13:851-7.

4. Sinha SK, Mishra V, Afdaali N, et al. Coronary angiography safety between transradial and transfemoral access. Cardiol Res Pract. 2016;2016:4013843.

5. Mattea V, Salomon C, Menck N, et al. Low rate of access site complications after transradial coronary catheterization: a prospective ultrasound study. Int J Cardiol Heart Vasc. 2017;14:46-52.

6. Avdikos G, Karatasakis A, Tsoumeleas A, et al. Radial artery occlusion after transradial coronary catheterization. Cardiovasc Diagn Ther. 2017;7:305-16.

7. Valsecchi O, Vassileva A, Cereda AF, et al. Early clinical experience with right and left distal transradial access in the anatomical snuffbox in 52 consecutive patients. J Invasive Cardiol. 2018;30:218-23.

8. Hallett S, Ashurst JV. Anatomy, Upper Limb, Hand, Anatomical Snuff Box. StatPearls. Treasure Island (FL)2018.

9. Robson AJ, See MS, Ellis H. Applied anatomy of the superficial branch of the radial nerve. Clin Anat. 2008;21:38-45.

10. Tanaka Y, Moriyama N, Ochiai T, et al. Transradial coronary interventions for complex chronic total occlusions. JACC Cardiovasc Interv. 2017;10:235-43. 